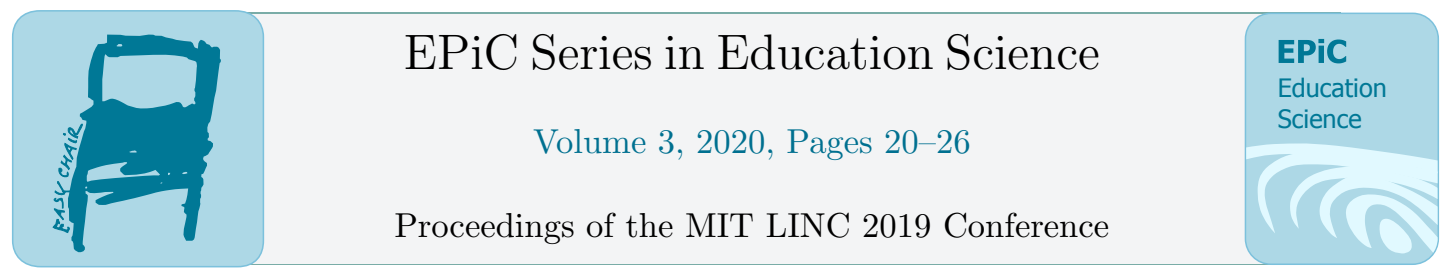

\title{
Gamified Approach to Blended Philosophy Course: Social Search and Multilingual Communication Experience
}

\author{
Mikhail Bukhtoyarov, PhD and Anna Bukhtoyarova \\ Siberian Federal University, Russia \\ mikebukhtoyarov@gmail.com, annabukhtoyarova@gmail.com
}

\begin{abstract}
The challenge of updating the existing curriculum to meet the requirements of blended, interactive and gamified approaches is complex. This article presents the design and results of the application of a gamified activity that was used to enrich a blended Philosophy course taught for two years and taken by more than 450 sophomore students in a large public university in Russia. The combination of social search with multilingual communication became an important educational experience for the participating students.
\end{abstract}

\section{Introduction}

Gamification is one of the rapidly growing trends today. According to Google Scholar the number of articles containing the term "gamification" increased from 340 published in 2008-2009 up to 20,700 published in 2018-2019 (according to search results in September, 2019). Numerous articles describe particular cases of e-learning gamification in higher education and gamified courses implementation in different universities worldwide.

Most of these practices are experimental as the gamified approach to online and blended university courses is still being developed. According to Wilson, Calongne, and Henderson, "there are no guarantees that the use of game design in an online course will lead to success" [1]. Hanus and Fox argue that "gamification in the classroom may be a double-edged sword" [2]. Current practices are being criticized for too mechanistic approach based exclusively on extrinsic rewards such as points, badges, and levels as they tend to focus too much on the formal game components.

As an alternative, Deterding discusses the term "gameful design" or "playful design" based on intrinsic reward, with positive emotions, relationships, meaning and 
accomplishment [3]. This concept emphasizes social components of gamification, discussing creating long-term motivation through a gamified activity rather than shortterm motivation based on behavioristic approach.

The authors argue that gamification is a tool that requires proper approach and application to become an effective one. So the instructional design based on gamified approach should be used not for the sake of the game per se. Gamified course design needs to comply with the high standards of tertiary education. At the same time it should be constructed around the learner's educational experience and rely on voluntary participation. Finding the balance between these two objectives is a challenge.

\section{Background: teaching Philosophy with e-learning tools}

Since 2005-2010 most universities in Russia have adopted e-learning technologies and have implemented major changes in their curricula, so that distance learning and blended learning are routinely used to deliver courses via university LMSs. The vast majority of such courses are based on instructional videos, digitized paper-based content (textbooks, graphs and illustrations, lecture notes, journal articles, etc.), inclass activities (discussions and quizzes), and various types of assignments submitted by the students electronically. Very rarely these courses are designed in accordance with constructivist approach and provide novel social experience to the students.

Since 2014-2015 the nation-wide utilization of the massive open online courses has become one of the most significant mainstream trends in Russian higher education. MOOCs have equipped the traditional instructivist approach with the powerful digital tools and gave it new life. In our opinion this tendency is the source of threat to the slowly emerging socio-constructivist trend which can be easily vanished with the currently dominating instructivist e-learning. The threat is especially dangerous for the Liberal Arts and Humanities component of the university curricula because strict instructivism can lead to degradation of academic freedom in such courses.

In Russian universities Philosophy is a part of the core curriculum according to the federal higher education standard. Three courses in Philosophy are taught mandatorily to students of all majors on every level of their academic path: undergraduate (an introductory course), graduate (Philosophy and History of Science course), and postgraduate (course in Philosophy of the particular research field). One of the most significant problems of teaching Philosophy in Russian higher education is massive application of the knowledge-based learning techniques and didactic method that utilizes memorization and reproduction of the information from the textbooks and lecture notes. The instruction at many universities is based on traditional lectures and colloquiums where students discuss texts, answer questions, and make formal conference-style presentations. In some cases such courses include project work, essays, and peer review activities. In recent years more innovative practices based on socio-constructivist paradigm have been adopted, yet they have not become the 
significant game changers due to the conservatism of the university Philosophy.

Currently many universities require Philosophy as well as other liberal arts and humanities courses to move to the distance or blended format. These requirements have been included in national educational standards. This has increased the domination of instructivism and has caused demotivational effect on the learners. As a result, students often see a blended course in Philosophy as a boring and timeconsuming formality with numerous online quizzes, links to library resources, long texts, and lack of social interaction.

Another issue is the specific nature of philosophical topics that are often quite vague and irrelevant to the students' everyday needs. This is especially the case with the students of technical majors as they are required to take this core course according to the federal standards. That causes the low level of initial interest in the subject and significantly poorer performance throughout the course demonstrated by less motivated students. According to the informal interviews conducted in the beginning of the Philosophy course less than half of undergraduate students want to study Philosophy as they consider it useless for their professional development.

\section{Instructional design concept}

Such a combination of issues within one course calls for the complex instructional design solution that would enrich the course with more flexible and open learning experiences in comparison with traditional instructivist approach. The goal was to design the entire 18-week course as a gamified quest with particular scores for every activity. Gamification was also chosen as the approach to increase motivation towards e-participation [4]. Face-to face and digital elements of the course are logically bound with each other to form a smooth journey for the learners. The whole course is divided into three units with different rules and goals. Most of the assignments can be completed in alternative formats (essays or videos, posters or presentations, etc.), so the students have freedom of choice on every stage of the course. Students earn the points for the completed assignments and can score bonus points for creativity.

The second major assignment of the first unit on the History of Philosophy is transformed into "the game within the game" called "Philosophical Hunting. Catch a Philosopher". The goal of this gamified activity is to maximize the participant engagement in order to establish the relevance between the course material and student personal experience through interaction with a philosopher. Students have to find philosophers from different universities around the world and take short interviews by the means of any available communication technology: social media, email, videoconferencing, messengers, etc.

The task is performed in randomly assigned groups of 3-5 students who prepare sets of questions and send them to philosophers (course of 2017) or Philosophy majoring students (course of 2018) from different countries. On the initial stage the students brainstorm, select and discuss questions based on the course topics and their 
own ideas about Philosophy. Then they use a variety of search tools and techniques to find interviewees in philosophical groups in social media or in professional online communities (university pages and groups). As the term "social search" is related to much bigger spectrum of social interactions than just the online ones the students are encouraged to use any of their resources such as friends, families and other social connections. Their task is not just to find a person engaged in Philosophy but also to try to introduce themselves and to obtain a permission for the interview. If they achieve the goal and the questions are answered the teams get the bonus points for successful communication. Extra bonus is given for application of foreign languages (other than the language of instruction). According to the rules, the use of English as a means of communication doubles bonus scores while the use of any language other than Russian or English triples them. Students are encouraged to use automatic translation tools if necessary. The most important criterion is meaningful communication demonstrating a "catch" - the philosopher's answers to students' questions.

As a result the student teams publish "trophies" (texts of the interviews with screenshots) in the discussion boards of the online course providing translation into Russian if necessary. The posts are followed by discussions during the face-to-face seminars in class. After the discussions every student writes a short reflective essay describing the "hunting" experience in both social search and communication.

As the main principle of a gamified approach is its freedom of choice, the students who are not willing to participate have two different options. They can either write a structured essay on the course topics or become bloggers covering the "hunting" process and publishing the observations online.

\section{Instructional design implementation results}

The suggested instructional design was implemented by three university teachers for two years and then was analyzed based on the quantitative data obtained from the student final reflective essays.

Comparing the results of two years in numbers we can see the difference in the "hunting" gamified activity outcomes. In 2017 the letters to the philosophers, who were mostly established academics, received replies only in 23\% (9 out of 39) of all attempts. These responses were available to all the teams for reviewing and discussing. Though the overall students' interest was quite strong the experience appeared to be less personal for the members of 30 teams who did not receive responses. In 2018, the "hunting" rules were changed so that the students were looking for the interviewees among the students majoring in Philosophy. The ratio of the received responses increased up to $92 \%$ (66 out of 72). This change made educational experience more successful and therefore encouraging for the teams and all the participating students.

After the "hunting" game the students were asked to write short reflective essays and answer the following questions about the experience they had had: Was it easy or difficult? What exactly was easy or difficult? What was your role in the team? Did you 
learn something new? As a part of their essays many of the students also expressed their general attitude towards this gamified activity even though they were not required to do so.

To obtain quantitative data we analyzed 164 short essays from the Spring 2017 course and 205 essays from Spring 2018 course. We retrieved students' expression on positive / negative attitudes towards the gamified activity, their clearly stated interest to it, and their evaluation of its difficulty / easiness. We calculated the amount of newly learned facts / received insights related to Philosophy which the participants had mentioned in their reflections. As we considered multilingual experience an important part of the gamified activity we also analyzed their reflections on foreign languages use expressed in the essays.

Based on the analysis of the responses from the students we can conclude that the developed gamified design of the entire blended course increases the engagement of the students in the course activities significantly. According to the students' essays, the "hunting the philosopher" was often described as an interesting and at the same time challenging experience. In 78\% (2017) and 80\% (2018) of the short reflective essays the students used the words "interesting" to describe the activity. Though at the same time about half of the participants (81 in 2017 and 105 in 2018) also found it "difficult" to perform.

Despite that difficulty, about $72 \%$ of the 2017 students and about $85 \%$ in 2018 emphasized in their essays that they liked the "hunting" without being asked about that. Surprisingly there was no correlation between the students' positive attitude to the activity and the philosopher's answers received by his or her particular team. As all of the "trophies" (texts of the responses) were openly available for all the teams on the course forum every participant felt connected to the positive results as if they were their own ones.

Many participants enjoyed informal communication through social media, and for the majority of students this activity became the first time when they were using these web platforms and services as a part of the formal course assignment. Social search in this context utilized "all kinds of information traces left by past users/searchers, both inside and outside social media systems" [5]. That is why students were addressing any people they could reach including diaspora representatives, friends, family members and other social connections they had. This was especially useful for searching Philosophy students in 2018.

Through the gamified activity some students were also training their critical evaluation skills and working with authentic philosophical texts. More than 50\% students in 2017 and about $40 \%$ in 2018 stated that they had learned something new and valuable on Philosophy while formulating the questions for philosophers. Some of the students even stated that their world view had changed in some way. While during 2017 some of them described the obtained knowledge as "deep" or "advanced", in 2018 a number of participants mentioned "diversity" they had not thought of before 
the "hunting".

As the activity design stimulates the use of different languages it provides multicultural context to the Philosophy course. Gamified approach encourages application of the foreign language for topic-based online communication. Formulating Philosophy questions for the representatives of different cultures motivates the students develop their cultural awareness. About $43 \%$ of the students in 2017 and $28 \%$ in 2018 stated that purposeful use of foreign language was an important factor for them in performing the task. Some of them emphasized that it was the first time they were using a foreign language for learning something other than the language itself.

Encouraging multilingual communication had an added value for the teams that included international students. Those members had an opportunity to apply the knowledge of their native languages and use personal connections to find a potential interviewee. In 2018 we could observe that the intercultural literacy of international students was on high demand and it often allowed their teams to achieve results easier comparing to the monocultural groups. At least four of 2018 student groups specified that having international members in their teams was especially useful in this context.

Based on the observation this "game inside the game" approach in the first unit functions as an icebreaking activity that has a long-lasting effect throughout the course. Such teamwork activity as formulating questions for the interviews makes students explore the material and discuss it to achieve the agreement inside the teams. While planning their search and interviews the students also have to practice their skills of teamwork coordination and time management.

In our opinion gamified social search and online communication can help overcome the issue of education gamification when it "most commonly utilizes affordances signaling achievement and progression, while social and immersion-oriented affordances are much less common" [6]. The suggested approach gives the personal relevance to learning philosophical concepts. It contextualizes quite abstract philosophical knowledge through meaningful gamified social activity. The designed teamwork makes the activity social both offline and online giving the students an opportunity to evaluate and train themselves in both modalities.

The word "experience" was used more than thirty times in the 2017 short essays and more than one hundred times in 2018. This experience was described by students as "positive, meaningful and useful for the future". The authors conclude that the proposed gamified activity efficiently motivates students, and it can be further utilized as a part of the Philosophy course.

\section{Discussion}

The major limitation of the described approach is the dependence of the game outcome on multiple uncontrollable or hardly controllable factors: interpersonal communication inside the pre-assigned groups, intercultural communication 
experience of the group members, their choice of search strategy, approach to the philosopher. The ethical and legal issues if arise also should be reviewed and addressed.

These uncontrollable factors need to be carefully monitored throughout the course to minimize their risks and potential harm. The cases of unsuccessful communication can be partially compensated with peer group reviews and discussions.

From the authors' point of view this complex approach involving a combination of social search, teamwork and intercultural communication requires carefully planned blended course design. Implementing "games inside the game" and encouraging students go beyond both face-to-face and online classrooms can facilitate in creating learning experience that is hardly possible to obtain in a more traditional Philosophy course. Gamified instructional designs within the higher education context need to be more experimented with to resist a purely instructivist approach and to create meaningful learning experience.

\section{Acknowledgements}

We thank Dr. Maria Kozlova and Dr. Lyudmila Elizova for their contribution to the course.

\section{References}

[1] D. Wilson, C. Calongne, and S.B. Henderson, "Gamification Challenges and a Case Study in Online Learning", Internet Learning, Vol. 4, Iss. 2, Article 8, 2014, pp. 84-102.

[2] M.D. Hanus, J. Fox, "Assessing the effects of gamification in the classroom: A longitudinal study on intrinsic motivation, social comparison, satisfaction, effort, and academic performance", Computers \& Education, Elsevier, 80, 2015, pp. 152-161.

[3] S. Deterding, "Make-believe in gameful and playful design", Digital make-believe, Springer, Cham, 2016. Pp. 101-124.

[4] L. Hassan, J. Hamari, "Gamification of E-Participation: A Literature Review", Proceedings of the 52nd Hawaii International Conference on System Sciences. January, 2019, pp. 3077-3086.

[5] P., Brusilovsky, B. Smyth, and B. Shapira, "Social search", Social Information Access, Springer, Cham, January, 2018, pp. 213-276.

[6] J. Majuri, J. Koivisto, and J. Hamari, "Gamification of education and learning: A review of empirical literature", 2nd International GamiFIN Conference, Pori, Finland, May, 2018, pp. 21-23. 